Europe's Journal of Psychology 1/2010, pp. 6-13

www.ejop.org

\title{
Ideas that shape contemporary psychology: Interview with Prof. Robert Sternberg
}

\section{By Vlad Glăveanu \\ EJOP Editor}

Professor Robert Sternberg is a scholar that needs no introduction for all those who are in contact with fields such as intelligence and creativity, thinking and problem solving, social relations and leadership, and thus, more generally, with the discipline of psychology. His prodigious scientific activity has greatly shaped our understanding of the human mind, of intelligent and creative behaviour, of the development of the intellect. Professor Sternberg's research stands out not only as a fundamental contribution to psychological theory but, above all, as an example of how psychological research can be extremely useful for different fields of human activity, from educational to organisational settings. In this interview Professor Sternberg talks about the past an present of intelligence and creativity research, and also about his career and current projects, a source of inspiration for graduate students, young scholars and psychologists at large.

Currently Dean of Tufts' School of Arts and Sciences and Honorary Professor at the University of Heidelberg, Robert J. Sternberg is the Director of the PACE (Psychology of Abilities, Competencies and Expertise) Center. His work at the PACE Center is dedicated to the advancement of theory, research, practice and policy advancing the notion of intelligence as modifiable and capable of development throughout the life span. Former IBM Professor of Psychology and Education and Professor of Management at Yale University, Robert Sternberg received his Ph.D. from Stanford University and his B.A. summa cum laude and Phi Beta Kappa, with honors and exceptional distinction in psychology, from Yale University. He has also received ten honorary doctorates. He is a past-president of the American Psychological Association (APA) and the Eastern Psychological Association (EPA), and has served on the Boards of Directors of the APA, APA Insurance Trust, and American Psychological Foundation. Robert Sternberg is currently on the Boards of the American Association of Colleges and Universities and the Eastern Psychological Association. 
EJOP: Prof. Sternberg, your outstanding career has been shaped by multiple interests. Alongside a key preoccupation for human intelligence and the related fields of creativity, wisdom, thinking styles, reasoning and problem solving, and intellectual development, you have made significant contributions to the study of social relationships, love and hate, social competences, leadership and ethnics, among others. Your theories have found numerous applications, predominantly in the psychology of education and school psychology. Are there any underlying themes or assumptions that permeate your work in all these different areas? How did your add, in time, more and more areas of interest and how do you see the connections between them?

Robert Sternberg: I pretty much pursued topics that interested me. Almost always, the topics followed from personal failures. I became interested in intelligence because I scored poorly on IQ tests as a child; I started studying creativity as a result of feeling bereft of ideas; I studied wisdom as a result of giving poor advice to a graduate student; I started studying love when I was in a failing relationship; I started studying hate because I lost much of my mother's side of the family during the Holocaust. In general, I think my theories take ideas that are fairly intuitive and commonplace, formalize them, and present them in a testable way. That is to say, none of the theories is particularly deep or insightful, but rather characterizes phenomena in common-sensical ways. Some scholars prefer to pick one topic and stay with it for their entire careers. This path, although probably the more rewarded one, would have bored me. I am easily bored, most of all, with my own work, so I tend to move on although never to abandon an area entirely.

EJOP: From past to present and also to the future. What are the projects you are working on at the moment in terms of research and/or publications? How do these projects continue or fit into the "big picture" of your previous work?

Robert Sternberg: My largest project right now is on university admissions-applying my WICS theory (wisdom-intelligence-creativity-synthesized) to the admission of students. We did a first project when I was at Yale, and now at Tufts, WICS has become a part of the admissions process for undergraduates. Basically, we found that by assessing WICS, we could increase prediction of first-year grade-point average and also of participation in extracurricular and leadership activities. Our assessments, unlike the commonly used SAT and ACT, do not show ethnic-group differences. This work will be summarized in a book to be published next fall by Harvard University Press, Seeking the Best. I also am involved in testing some of the predictions of the balance theory of wisdom. Also in press is a coauthored book, 
Explorations of Giftedness (Cambridge University Press), and coedited new editions with Cambridge of my handbooks of intelligence and creativity.

EJOP: You are one of the main contemporary theorists of intelligence and have greatly influenced the psychological study of this phenomenon in your career spanning almost four decades. How would you appreciate the current state of the psychology of intelligence compared to the time when you started working on the triarchic theory? What has been and has not been yet achieved by research on intelligence? Where should we look to next?

Robert Sternberg: On the positive side, there is a lot of excellent work going on, especially in the cognitive area, looking at relations between constructs such as working memory and attention, on the one hand, and intelligence, on the other. Great progress has been made in understanding brain correlates of intelligence, although sometimes the investigators forget that they are indeed studying correlates whose causal roles are not yet clearly demonstrated. There has also been a great deal of excellent work on cultural aspects of intelligence and on educating students to increase their intelligence. The work on the Flynn effect also has been fascinating. On the negative side, there has been less development theoretically than I had hoped. Many people are still stuck on $g$ theory and doing endless studies showing that $g$ correlates with this and that. They seem to lack the capacity to be bored, as they keep finding new things with which to correlate $g$, and indeed, the number of potential constructs is probably infinite so they will be assured of having something to do for the rest of their careers, as will their successors. There is also a group that is obsessed with showing that people like them are smarter than people who are not like them, but I suspect that will always be the case. Some of the people attracted to the field are attracted because it helps them deal with their own insecurities. (Take me, for example: I study intelligence because of my poor childhood intelligence test scores!) Indeed, sometimes I go to parties and talk to people who manage to slip in their standardized test scores from their youth. In some cases, that may be the last great thing they did.

EJOP: Your triarchic model of intelligence emphasized the role of creativity for intelligent behavior. You expanded your work on creativity through time and proposed, with Todd Lubart, new models such as the investment theory of creativity. At the same time, comparing intelligence and creativity research in psychology in general, the latter seems rather underdeveloped. How would you appreciate the current state of the psychology of creativity? What have we gained in the past decades and what is still ahead of us in terms of pressing questions and challenges? 
Robert Sternberg: The psychology of creativity has moved forward greatly. I am currently coediting a new Cambridge Handbook of Creativity with James Kaufman, which updates my earlier handbook, and contains a summary of current research. Great progress has been made in understanding personality attributes underlying creativity, brain correlates of creativity, and techniques for developing creativity. I would have hoped to see more gains in applied research-for example, new ways of teaching for creativity and innovative ways of measuring creativity that could become part of standardized testing batteries. Instead, many educators are still using the Torrance Tests, which were innovative when they were introduced but now are very old. It is a bad sign when old tests hold on, because it means that the field of assessment is not moving. Of course, the whole testing industry is stuck in a retrograde early twentieth-century mentality, so the use of the Torrance tests is hardly surprising. The problem is that there is so little innovative competition. If testing companies faced the kind of competition software companies do, they would all have been driven into the ground long ago. But even the dinosaurs eventually lost their dominion over the world.

EJOP: Continuing the discussion of the triarchic model, you have emphasized the role of wisdom for human thought and behavior. And yet the concept of wisdom is somehow unfamiliar to psychologists and much more associated with philosophical inquiries into human nature. Why do you feel we need this concept and how can we go about measuring wisdom in psychological research?

Robert Sternberg: I became interested in wisdom in part because I once gave bad advice to a graduate student. I was about 30, and suppose I was smarter than I was wise. I also became interested because in the 1980s and 1990s, there were so many smart people doing stupid things. Very smart and well-educated people were bringing down companies and committing genocides. Little did I know that by 2008 , some of the smartest and best educated people would bring down the world economy, and having done so, been concerned only with how to profit from the misery they created. In the United States, at least, there are very clever people at major investment banks who, having screwed the public once, are now trying to do it again by profiting from the losses they caused others. I think we really need to pay more attention to wisdom and ethics, lest the future of the world be destruction wrought by our own cleverness (financial ruin, ruin by biological or chemical or nuclear attacks, or whatever). The best psychologist studying wisdom was Paul Baltes. He really opened the field up. I am so pleased that others are now following in his shoes. I am pleased that the Templeton Foundation is supporting research on wisdom: It is what the world needs. 
EJOP: Moving from analytical to creative and especially to practical skills as part of intelligence, more and more emphasis is given to the contextual nature of intelligent behaviors and, consequently, the need to take context into account in the assessment of intelligence. Defining what is creative and what is a successful application of knowledge and analytical skills is only possible if we understand the situational aspects of intelligent action. Your work has paid tribute to this nonuniversalistic understanding of what intelligence is and can help us become. At the same time the main drive behind psychometric studies has always been that of standardizing conditions and working with rather "universalistic" criteria. How do you think one can solve dilemmas such as the above? More generally, how do we manage to respect the particular circumstances of the respondents in intelligence testing?

Robert Sternberg: In the theory of successful intelligence, which was presented to me while I was on a mountain and was written on a tablet by a holy angel (only kidding), there is a universal part-the components of intelligence-and a culturespecific part-the application of these components to experience in real-world contexts. That is, in any culture, people must recognize when they have a problem, define what the problem is, figure out how to solve the problem, monitor their problem solving, and so forth. But the contexts in which they apply these components differ. For example, defining a problem as one of free speech to present dissent can bring you accolades in one culture and death in another. So I believe that there are universal but also culture-specific aspects of intelligence. When we use an intelligence test, we need to recognize it may not be measuring the same thing in one culture as another, even if it has been translated.

EJOP: A great part of your work at this point is dedicated to WICS - wisdom, intelligence, creativity, synthesized - proposed as an integrated model for instruction and assessment. What are the main principles that should inform teaching according to the WICS model? Correspondingly, what should be the main principles to inform student assessment?

Robert Sternberg: The main idea is that we should teach and assess in a variety of ways that enable all students to capitalize on their strengths and correct or compensate for their weaknesses. In our own research, we have found better student learning outcomes when students are taught analytically, creatively, and practically, as well as for memory. We also now infuse wisdom-based thinking into our curricula. Too often, teachers teach the way they were taught and assess the ways they were assessed. The result is that little changes. Students might actually be able to excel if taught in ways that better suit them. One of the disappointments in 
my own career is that I have found many scientists to be quite conservative and protective of the status quo. After all, it got them where they are, so it must be pretty good, and those who could not cut it based on that status quo-well, tough on them! As a dean, I find that scientists on the whole are much more conservative than people in the humanities, and in psychology, the scientists are more conservative than the practitioners, on the average. There is nothing wrong with being conservative, but in education, it results in stagnation. We are still, in the US, doing what we have done for over 100 years and will probably keep doing it as those in power continue to justify the system that put them into their positions of power and that will ensure their children benefit as well. I hope I am not being cynical. It is just how people are, and why at times we need revolutionary thinkers in science and in everything else, a point Tom Kuhn made 40 years ago!

EJOP: Besides being a renowned theorist and researcher you have built a strong reputation for putting your research intro practice. The "Rainbow" and "Kaleidoscope" projects are clear illustrations of this. Without disregarding more "traditional" measures (like SAT scores) you advocated for the introduction of tasks that require the use of creative and practical skills as integral parts of candidates' assessment process. What are the chances of this becoming common practice in the near future? What kind of challenges did you face in applying this new assessment strategy? Overall, is the educational system ready for integrating these novelties?

Robert Sternberg: Kaleidoscope is based on the notion of assessing and teaching for analytical, creative, practical, and wisdom-based skills. It is now part of what we do at Tufts, but whether it will continue beyond my deanship, I cannot say. Other schools have started using some of our methods as well. It is an uphill battle as there are strong vested interests in the conventional system. In the US, testing companies make money; universities don't have to pay-the students pay for the tests-so they feel free to continue to require them; news magazines evaluate universities based on their test scores so universities keep trying to raise their averages. It is a vicious circle, in a way, with one part of the system feeding off another. I greatly underestimated, when I was young, how hard it is to change a system, or at least, my own ability to change it. The keenest disappointment of my professional career is how little success I have had in changing anything that matters-a rather sorry record for 35 years of effort!

EJOP: Towards the end of our interview I would like to ask you to address a few words to our readers. One of our aims with Europe's Journal of Psychology is to promote an active dialogue between scholars, young professionals and graduate students. As 
one of the most prolific researchers in psychology and as a scholar who offered us around twelve hundred publications until now, what would you advise students pursuing a career in psychology?

Robert Sternberg: I tend to have three-part theories, so I would give three pieces of advice. First, find your passion and study that. There is a lot of pressure to study certain areas over others-those where the money is, those where one's friends are, those where the job openings are. It is sad how fad-driven psychology is. In the United States, at least, someone in the bottom 1/3 of cognitive-neuroscience researchers will have an easier time finding a job than someone in the top 1/10 of creativity researchers. So it is with many subfields-the money is here but not there. That said, the most creative and meaningful research is always done in the areas for which one has passion. Second, do not let conventional thinkers discourage you from moving a field forward. Psychology is filled with tradition-bound thinkers, many of them with very high IQs, who are frightened by the idea that traditional paradigms might be inadequate. Remember, there was a long period of time in which people who studied the mind were considered quite unscientific by the reigning behaviorists. Unfortunately, we select highly in our universities for correlates of $I Q$, and this is a very conservative way of selecting people-it tends to select for those who are good at playing the conventional game, which is essentially what IQ is a measure of. I have had more negative reviews of my work than most people will ever have reviews, positive or negative. Third, learn from your mistakes and don't get stuck. We all make mistakes and sometimes it is hard to admit to them. In my own work, my theories have moved from being rather narrow to being much broader. Every few years, I would recognize that the way I defined problems was more limited than I realized at the time. We need to spend more time thinking about what the big problems are before we rush to solve the small ones.

EJOP: Finally, what do you think is the role of psychology in the contemporary world? What is/are the main contribution(s) it made or has to make in the coming future to strengthen its role as one of the most dynamic and important fields of scientific inquiry?

Robert Sternberg: Psychology has many important contributions to make. In the US, I have started as President-Elect of the Federation of Association of Behavioral and Brain Sciences, and my major role is to educate policy-makers regarding what we are psychologists can do for society. We can make a difference to education, physical and mental health (which of course are closely connected), industry, and politics, to name a few domains. We as a field often have a compulsion to imitate biology and other natural sciences. It is great that our scientific progress can in some 
ways mirror those. But I hope that, in our rush to be part of the natural sciences, we do not lose concern with issues of values, ethics, and how to use our science for the common good. 